\title{
Walter Benjamin: Rastro, aura e história
}

\author{
Sabrina Sedlmayer, Jaime Ginzburg (Orgs.) \\ (Belo Horizonte: Ed. UFMG, 2012) \\ Lisa Carvalho Vasconcellos
}

Universidade de Sáo Paulo São Paulo, SP, Brasil

Em 1935, Erich Auerbach escreve uma triste carta a seu colega Walter Benjamin. Nela, o autor da Mimesis explica que suas pretensóes de obter para o colega um posto na Universidade de São Paulo, que então se formava, haviam sido completamente frustradas. $\mathrm{Na}$ época, para ambos os intelectuais, que compartilhavam também a origem judaica e a nacionalidade alemã, a emigração parecia ser a única saída de uma Europa cada vez mais beligerante e totalitária. Sabemos que Auerbach, pouco tempo depois, de fato se exilou na Turquia, sendo obrigado a deixar para trás sua biblioteca e os muitos trabalhos que conduzia; sabemos também que Benjamin, entretanto, náo teve a mesma sorte: ele morreu em 1940, durante uma última e fracassada tentativa de fugir à perseguição e à guerra, na travessia dos Pireneus já quase em solo espanhol. Pressentiria ele, entấo, que sua obra faria anos depois o caminho que não conseguiu fazer pessoalmente, com os próprios pés? Afinal, se o próprio Benjamin não conseguiu atravessar o oceano, seus trabalhos têm hoje aqui, do outro lado do Atlântico - no país que um dia poderia ter vindo a habitar - uma rica e fértil recepção.

Segundo Hannah Arendt, "a fama póstuma parece ser o quinhão dos inclassificáveis".* Benjamin, a quem a frase se refere, foi um autor cuja obra náo se adequava à ordem de sua época: sem ser propriamente um historiador, um teólogo, um filósofo da linguagem ou um crítico da literatura e da arte, escrevia sobre história, teologia, estética e literatura indistintamente, misturava áreas e saberes constituindo uma forma própria de lidar com o mundo e com o conhecimento. ${ }^{1}$ Nos dias de hoje, nos quais a valorizaçáo da interdisciplinariedade e da interpenetração de saberes vai se tornando o caminho

\footnotetext{
${ }^{1}$ Vide Theodor Adorno, em "O ensaio como forma". In: Notas de literatura I. Tradução e apresentação de Jorge de Almeida. São Paulo: Duas cidades; Editora 34, 2003.
} 
prioritário, seu trabalho se torna particularmente atual. Prova disso é que no Brasil, sua acolhida não se limitou aos campos mencionados acima, mas se espraiou e vem se espraiando pelos campos da psicanálise, da arquitetura, da sociologia e, principalmente, da teoria literária, disciplina que recentemente tem se expandido para dar conta não só de objetos artísticos, mas também dos discursos e das narrativas que compóem o vasto panorama da cultura.

O volume Walter Benjamin: rastro, aura e história, lançado pela Editora UFMG, no segundo semestre de 2012, é um bom exemplo do que afirmamos. Fruto de um trabalho coletivo, o livro é a mais nova produção do Núcleo Walter Benjamin, grupo coordenado, entre outros por Georg Otte e Élcio Cornelsen e que, desde 2006, se dedica à pesquisa e à divulgação dos trabalhos do pensador alemão. O livro reúne em forma de ensaios as principais comunicaçóes dadas à luz durante o segundo Colóquio Internacional do núcleo, intitulado "Spuren: rastros, traços, vestígios" realizado em 2010 na Universidade Federal de Minas Gerais e acrescenta, a esse material, contribuiçóes de convidados, que vem enriquecer e ampliar o projeto inicial. O resultado é um volume amplo e diversificado que mistura reflexóes teóricas exclusivamente benjaminianas (como as de Rolf-Peter Janz e de Jeanne Marie Gagnebin, que procuram delimitar filosoficamente os conceitos aura e rastro, fundamentais para as posteriores discussões do livro) com trabalhos de natureza comparatista (como, por exemplo, os de Paulo César Endo e Michele Cometa, que procuram estabelecer a relação entre Benjamin e outros pensadores, no caso Sigmund Freud e o historiador italiano Carlo Ginzburg), e ainda com trabalhos nos quais os conceitos e formulaçóes de Benjamin são usados na abordagem de realidades outras (como fazem Márcio Seligmann-Silva, ao usar o conceito de rastro para abordar a obra da artista plástica Regina Silveira, ou Willi Bolle, que procura ler a cidade de Belém a partir dos mesmos protocolos que Benjamin mobiliza para ler Paris, na obra das Passagens; vale lembrar, entretanto, que seu paradigma de modernidade não é mais Baudelaire, mas Dalcídio Jurandir, escritor paraense e o seu romance Belém do Grão-Pará).

Como o próprio título dá a entender, para todos esses autores serão essenciais os conceitos de rastro e aura. Ambos fazem refe-

* (SEDLMAYER, Sabrina e GINZBURG, Jaime (Org.). Walter Benjamin: rastro, aura e história. Belo Horizonte: Ed. UFMG, 2012: 13.) rência a realidades fugidias e às expressóes usadas para se referir aos dois não o são em menor medida. "Aparição única de uma coisa distante, por mais perto que esteja”* é uma das definiçōes de aura 
elencadas por Rolf-Peter Janz. "Presença de uma ausência e ausência de uma presença" é como Gagnebin define rastro. Ao longo dos textos, esses conceitos se alternam colocando em oposição duas realidades diferentes, mediadas pelo terceiro item da tríade que dá título ao livro, a história. Se no passado os objetos históricos (a obra de arte em especial) eram cercados de uma aura que lhes conferia valor quase religioso, hoje, no contexto de sociedades pós-industriais, só podemos entrar em contato com o passado através de seus rastros.

Em dois artigos específicos esses conceitos são empregados em situaçóes particularmente interessantes para a reflexão sobre o mundo contemporâneo. Em "A interpretação do rastro em Walter Benjamin" de Jaime Ginzburg, o rastro é elegido como concepção fundamental para o entendimento da realidade brasileira em seus recalques e não ditos. Já em "A memória poética da guerra colonial de Portugal na África: os vestígios como material de uma construção possível”, de Roberto Vecchi e Margarida Calafate Ribeiro, o rastro vai ser o elemento que permitirá a construção de uma memória da guerra no contexto pós-colonial português, utilizando para isso a produção poética (canônica e não canônica) disponível sobre o assunto.

No primeiro desses artigos, Jaime Ginzburg partirá de uma diferenciação básica no que diz respeito ao conceito de rastro para problematizar as especificidades da realidade brasileira (e da sua representação artística). Para isso, o professor e pesquisador se dedica ao estudo comparativo de dois teóricos importantes: o historiador Carlo Ginzburg e o próprio Walter Benjamin. Para o primeiro, o rastro é compreendido como parte constitutiva de uma narrativa a ser formada. Em sua acepção mais básica, o rastro é a marca (a pegada) deixada por um animal em seu caminho. Cabe ao caçador, recompor, a partir dessas marcas, um percurso que o permita encontrar o animal buscado. Para Carlo Ginzburg, o historiador deve agir como um caçador, selecionando "os principais elementos decisivos para a compreensão do passado"* e formando a partir deles a narrativa a que chamamos história. A concepção de Benjamin sobre esse mesmo assunto, entretanto, não poderia ser mais diferente. Segundo Jaime Ginzburg, ele "entende a interpretação do humano em pautas que envolvem componentes dissociativos e cindidos", * ou seja, em sua concepção, o rastro não seria necessariamente encaixável em uma narrativa linear e totalizadora, mas produziria cortes, esquecimentos e dissonâncias. 
Ao estudar as especificidades do caso brasileiro (das suas narrativas históricas dominantes, das suas elaborações conceituais, da formação das suas instituições), ele encontra muitos exemplos desses cortes e disjunçóes. Enquanto país, viemos, no Brasil, ao longo de nossa história, reprimindo as memórias da violência estrutural e formadora do país: a destruição de povos indígenas, a escravidáo africana, o massacre de Canudos, a repressão e os assassinatos durante os regimes de exceção (com a ditadura civil-militar de 1964 em primeiro plano). Todos sáo episódios do nosso passado que preferimos deixar de lado, numa verdadeira política do esquecimento. Ainda segundo Ginzburg, a literatura brasileira dá testemunho formal de uma desconfiança legítima em relação às narrativas falsas e totalizadoras. Bons exemplos disso são, nessa perspectiva, os narradores pouco confiáveis de Machado de Assis, Guimarães Rosa, Graciliano Ramos ou mesmo Raduan Nassar. Tanto Bentinho, como Riobaldo, Paulo Honório ou André desprezam a linearidade e a causalidade das estórias que contam e se revelam sempre hesitantes e desconfiados da própria memória.

O segundo artigo é quase um corpo estranho dentro da coletânea. Sem se dedicar especificamente a Benjamin ou a realidades próximas ao contexto brasileiro ele faz, entretanto, um movimento muito interessante de buscar no rastro benjaminiano as bases para a construção literal de uma memória coletiva. É preciso deixar claro que esse processo não tem ambiçóes totalizadoras; muito pelo contrário, é uma memória falha, estilhaçada e fragmentada a que se desenha através desse esforço. Talvez a única memória possível em uma situação de guerra generalizada. Expliquemos. $\mathrm{O}$ artigo de Roberto Vecchi e Margarida Calafate Ribeiro vem debater teoricamente os princípios de uma coletânea poética elaborada pelos próprios autores - a Antologia da memória poética da Guerra Colonial. O livro procura, nas palavras de seus próprios organizadores, recolher um corpo textual que paute os principais temas e problemas da produçáo poética feita no e a partir do período da Guerra Colonial portuguesa (1961-1974). Nesse sentido, os conceitos benjaminianos de rastro, vestígio e ruína se revelaram essenciais, como afirmam Vecchi e Ribeiro, uma vez que fundamentaram as questóes iniciais a partir das quais foi possível se desenhar um corpus para o trabalho. É preciso lembrar que o conflito colonial foi uma experiência praticamente universal dentro da realidade portuguesa da época, mobilizando algo em torno de um milháo de soldados e atingindo 
quase todas as famílias do país, independentemente da classe social. A produção artístico-literária que lida diretamente com o assunto é igualmente profusa, daí a dificuldade e ambição da tarefa.

Elegido um material de trabalho, a tentativa dos autores foi então a de abordar os poemas e fragmentos textuais que compóem o livro como rastros, que, lidos em sequência, comporiam uma narrativa incompleta, mais ainda assim uma narrativa. $\mathrm{O}$ modelo usado para isso é novamente o do caçador, que recompóe o percurso de sua presa a partir das pegadas deixadas por ela. Ao contrário da narrativa linear e causal de uma caça, a memória recomposta pelos poemas seria uma memória em perigo, ou ainda uma memória em disputa. E isso se dá não só porque aquilo que os poemas buscam partilhar faz oposição direta à política de esquecimento adotada pelos órgãos oficiais do país, mas também pelo caráter traumático dessa própria memória. A experiência avassaladora e sem sentido da guerra se erige nesses textos como fato não simbolizável, como ruína e signo (mudo) de morte, e instaura, assim, um tempo recursivo, não linear dentro do qual é impossível enterrar o passado. Não é sem razáo que o corpo insepulto será, como lembram os autores do ensaio, um tema recorrente na literatura portuguesa de guerra. Como um fantasma a materialidade do império desfeito sem impóem sem "nenhuma totalidade ou sentido possível”* resistindo à amnésia do mundo da técnica.

* (Ibidem: 98.)

Assim como os dois artigos mencionados acima, muitos outros da coletânea Walter Benjamin: rastro, aura e história mereceriam uma leitura mais prolongada aqui. As limitaçóes da presente resenha impedem, entretanto, uma análise maior ou mais detalhada. Fica registrado aqui o convite para que o leitor dê continuidade a esse trabalho, através da leitura desse livro que, como queremos enfatizar, é fundamental para a compreensão seja do Brasil, seja de outras realidades.

Lisa Carvalho Vasconcellos é doutora em Teoria Literária pelo Departamento de Teoria Literária e Literatura Comparada da Faculdade de Filosofia, Letras e Ciências Humanas da Universidade de São Paulo. E-mail: $<$ lisa.vasconcellos@gmail.com> 